\title{
Recognising pathological grief
}

Karien Botha, MB ChB, MMed (Psych)

Room 3, Medi-Clinic, Berlyn Street, Paarl, W Cape

As an inevitable end to life, death is one of the most denied experiences all of us will go through. As young people, we tend to think of ourselves as invincible.'

By the age of 65 , over half of all women and over $10 \%$ of all men have been widowed at least once. Among those who survive 85 years or more, $81.3 \%$ of women and $40.5 \%$ of men are widowed. ${ }^{2}$

Grief is defined as the expression of our reaction to loss.

Mourning involves the process of reorientating ourselves in relation to the deceased, the self and the external world.

The bereavement literature has not yet reached consensus on a clear definition of normal and abnormal or complicated (pathological) grief reactions. There have, however, been attempts to examine the validity of specific grief outcome categorisations in relation to available empirical data. ${ }^{3}$

\section{Presentation of normal grief}

The stages of normal grief have been described in many different ways over the years.

Grief is an individual process (not necessarily a linear process), composed of fluid phases, which can vary in duration from months to years. ${ }^{4}$

Most bereaved individuals experience four types of disruptive functioning in the first year after their loss: cognitive disorganisation, dysphoria, health deficits, and disruption of social and occupational functioning. ${ }^{3}$

\section{Cognitive disorganisation ${ }^{3}$}

\section{Confusion and preoccupation}

Bereaved individuals often have difficulty in accepting the reality of their loss, accompanied by a sense of disbelief, de-realisation, disorganisation and preoccupation. A percentage describe difficulties in concentration and making decisions.

\section{Disturbance of identity}

Bereaved individuals describe a sense of loss of identity, a feeling that 'a piece of me is missing'. A portion find that they are doing things more like their deceased spouses or even experiencing the same physical symptoms as the deceased. The bereaved often experience recurrent thoughts of their own death.

\section{Sense of disrupted future}

In the early months after a loss, the majority of bereaved individuals report uncertainty about the future; they tend to experience a sense of hopelessness and to perceive a foreshortened future.

\section{Long-term search for meaning}

Bereaved individuals are often preoccupied with a way to understand or find meaning in their loss. They often describe the world as being less meaningful and feel that personal circumstances are determined by chance or by powerful others. Even as late as $4-7$ years after the sudden loss of a spouse or child the vast majority continue to talk about the loss and ask the question 'why?'. Sixty-eight per cent of bereaved spouses and $59 \%$ of bereaved parents report that they cannot make any sense of the loss.

\section{Dysphoria $^{3}$}

\section{Distressing emotions in the bereavement process}

Anger, irritability, hostility, sadness, fear and guilt may occur in the bereavement process. Guilt is often the result of feeling responsible for the death or suffering of the deceased, or a type of survival guilt. The guilt feelings may be linked to 'sins of omission', i.e. the person may feel that there was something more that $s /$ he could have done to prevent the death of the deceased or to have made the deceased more comfortable before their passing. Anger is often directed at the deceased, the family, God, physicians or at the bereaved him/herself. ${ }^{3}$

\section{Pining or yearning ${ }^{3}$}

The most central feature of grief is an intense 'pining' or yearning for the deceased, such that without it, grief cannot truly be said to have occurred. 


\section{Loneliness $^{3}$}

An intense feeling of loneliness, even when around other people, is commonly associated with grieving. Changes in some aspects of identity and role change after the loss of a spouse, e.g. being a single parent, being single again and learning about one's own capacity to cope with tasks and to find new ways of dealing with the world, can increase the sense of loneliness. Friends are often overwhelmed by the intensity of the survivor's need and may, as a consequence, withdraw.

\section{Health deficits}

\section{Health behaviours and complaints}

An increase in the number of doctor's visits and general health complaints has been observed among recently bereaved individuals. Symptoms are often vague, without demonstrable disease, and the duration varies and can persist for $1-3$ years. ${ }^{4}$ Typical symptoms include shortness of breath, palpitations, digestive difficulties, loss of appetite, restlessness and insomnia.

\section{Immune functioning}

Bereaved individuals show reduced T-cell responsivity and compromised immune functioning.

\section{Mortality}

Increased mortality appears to be particularly high in the early months after a loss, and is higher among men than women. Death by natural causes is almost twice as high as the normal rate in the first week of bereavement. In addition, death by violent causes, e.g. traffic accidents, is also much more common in this group.

There are considerably more deaths by suicide among bereaved individuals than in the general population, with a $242 \%$ increase in this regard.

\section{Disrupted social and occupational functioning}

The majority of conjugally bereaved individuals withdraw from participation in social activities in the early months after the loss, but more than half show increased activity by the end of the first year. Individuals appear to struggle in their work roles, in managing spare time, and in adjusting in their family roles.

Temporary difficulties exist in initiating and maintaining new intimate relationships. Widows are relatively slower to engage in new romantic relations. Widowers are more likely to remarry, especially if they are young. Regardless of gender, bereaved individuals who are depressed find it more difficult to begin new relationships.

\section{Restitution}

'As time goes on the survivor "survives": that is, learns of his or her capacity to tolerate the grief, carry on tasks and discover new ways of dealing with the world; new feelings and self-images may emerge. ${ }^{4}$

A stronger sense of self, autonomy, independence, assertiveness and maturity present. Survivors often become more compassionate, patient and balanced as people. 'With time and continued survival and growth, the bereaved may have the opportunity and capacity to transform their tragedy into new directions; careers, relationships and personal evolution. ${ }^{3}$

People use different types of mechanisms to work through their grief, ${ }^{4}$ e.g. intellectualisation (observing the grieving process from a distance), rationalisation (transforming an awful truth into an acceptable one, e.g. 'the deceased is better off dead'), humour (remembering humorous episodes), passive distraction (listening to the radio or watching television), or active involvement with others.

Faith allows survivors to accept the death as part of God's plan, and reassures them that the deceased will be cared for and is not alone. Religious rituals offer an opportunity for ongoing connection with the deceased (e.g. Catholic anniversary mass, Jewish Yizkor). ${ }^{5}$

\section{Defining pathological grief}

'Where grief for a particular individual, in a particular culture, appears to deviate from the expected course in such a way that it is associated with excessive or prolonged psychological symptoms', ${ }^{6}$ It can be described as complicated/abnormal/ atypical/prolonged/unresolved or dysfunctional grief.

Individuals showing little or no grief have always been viewed with suspicion as having some form of inhibited or masked grief, or as being prone to develop delayed grief symptoms. However, this could be an indicator of adjustment and should not necessarily be considered pathological. There does not appear to be any concrete evidence that minimal grief in the early months of bereavement will eventually lead to delayed grief. ${ }^{3}$ 


\section{Diagnostic criteria for pathological grief}

According to the Diagnostic and Statistical Manuals of Mental Disorders (4th ed.) (DSM M ${ }^{7}$ the death of a close friend or relative is a stress with generally normative and predictable consequences. Bereavement is considered among the ' $\mathrm{V}$ ' codes and is used diagnostically when the focus of clinical attention is a reaction to the death of a loved one.

'As part of their reaction to the loss, some grieving individuals present with symptoms characteristic of a Major Depressive Episode (e.g. feelings of sadness and associated symptoms such as insomnia, poor appetite, and weight loss). The diagnosis of Major Depressive Disorder is generally not given unless the symptoms are still present 2 months after the loss. However, the presence of certain symptoms that are not characteristic of a "normal" grief reaction may be helpful in differentiating bereavement from a major depressive episode. These include: (i) guilt about things other than actions taken or not taken by the survivor at the time of the death; (ii) thoughts of death other than the survivor feeling that he or she would be better off dead or should have died with the deceased person; (iii) morbid preoccupation with worthlessness; (iv) marked psychomotor retardation; ( $v$ ) prolonged and marked functional impairment; and (vi) hallucinatory experiences other than thinking that he or she hears the voice of, or transiently sees the image of, the deceased person. $^{17}$

DSM IV does acknowledge that cultural forms of mourning and grief behaviour exist and that the duration of normal bereavement varies considerably among different cultural groups.

\section{Criteria for traumatic grief}

Prigerson et al. ${ }^{8}$ conclude that DSM N negates the substantial evidence that symptoms apart from those of depression may constitute a distinct psychiatric syndrome, i.e. symptoms of traumatic grief. They proposed the following consensus criteria for traumatic grief. ${ }^{8}$

\section{Criterion A}

The person has experienced the death of a significant other.

The response involves distressing, intrusive preoccupation with the deceased person (e.g. yearning, longing or searching for the deceased).

\section{Criterion B}

In response to the death, the following symptoms are marked and present: (i) frequent efforts to avoid reminders of the deceased (e.g. thoughts, feelings, activities, people, places); (ii) purposelessness or feelings of futility about the future; (iii) subjective sense of numbness, detachment or absence of emotional responsiveness; (iv) feeling stunned, dazed or shocked; (v) difficulty acknowledging the death (e.g. disbelief); (vi) feeling that life is empty and meaningless; (vii) difficulty imagining a fulfilling life without the deceased; (viii) feeling that part of oneself has died; (ix) shattered world view (e.g. lost sense of security, trust, control); $(x)$ assumes symptoms or harmful behaviours of, or related to, the deceased person; and (xi) excessive irritability, bitterness, or anger related to the death.

\section{Criterion C}

The duration of the disturbance (symptoms listed) is at least 2 months.

\section{Criterion D}

The disturbance causes clinically significant impairment in social, occupational, or other important areas of functioning

\section{Risk factors for developing pathological grief}

Risk factors are as follows: (i) the circumstances of the death are important - the risk of pathological grief is higher if the death has been sudden, unforeseen, untimely, painful or horrifying or if the bereaved or another person is in some way to be blamed for the event; ${ }^{9}$ (ii) bereavement resulting from suicide; ${ }^{9,10}$ (iii) past history of major depression ${ }^{11}$ or any other previous mental illness; ${ }^{10}$ (iv) borderline personality disorder; ${ }^{2}$ ( $v$ ) loss of a child; ${ }^{3,11}$ (vi) death after a prolonged illness; ${ }^{3}$ (vii) a pre-morbid relationship with the deceased that has been markedly angry, ambivalent or overly dependent; ${ }^{3,10}$ (viii) people who possess insecure attachments, specifically individuals with excessively dependent, compulsively caregiving, or defensively separated attachment styles; ${ }^{2}$ (ix) a history of an unsettled childhood and of being raised to bottle up feelings; ${ }^{3}(x)$ previous unaccommodated losses and stresses; ${ }^{3}$ (xi) lack of social support; ${ }^{3,11}$ and (xii) AIDS-related death (stigmatised deaths). ${ }^{10}$

Identifying individuals at risk may provide the opportunity for planned preventive intervention. 


\section{AIDS-related bereavement}

Two characteristics of AIDS are important in understanding grief reactions following AIDS bereavement: firstly, the long period of anticipation of death, and secondly the unpredictable course of the illness. A quiescent state of asymptomatic infection with HIV may have a duration of 10 years. Guilt feelings often exist especially after caring for someone in an advanced stage of the illness, with the carer wishing for the death of the individual. ${ }^{12}$

AIDS bereavement is associated with higher levels of symptoms of severe psychological distress. Usually AIDS-related death follows a long and intensive fight for life. Bereaved male partners of AIDS victims experience more of the following symptoms than those widowed through other causes: depression, helplessness, hopelessness, sadness, sleep disturbance, somatic complaints, cognitive impairment, suicidal ideation and actual suicide attempts, traumatic stress responses, e.g. nightmares, panic attacks, numbing, preoccupation with one's body in terms of signs of AIDS, and fear of developing AIDS.12

AIDS grievers are referred to as 'disenfranchised grievers'. Death as a result of AIDS is often stigmatised (as is suicide). AIDS grievers are often denied access to communal support as the community often questions the legitimacy of their grief, or stigmatises the death. Successful grief resolution requires the community to extend its boundaries to sanction the relationship so that these grievers can take their place publicly in the community of mourners.

\section{Gender differences in experiencing grief}

Men who have lost their spouses tend to be more vulnerable to psychological and physical illness and are at greater risk of death than women who have been widowed. It seems that women have better social support resources and are more likely to have at least one close confidante outside the marriage than men. ${ }^{13}$

\section{Biological correlates of the grief process}

\section{Neuroendocrine system}

Six studies ${ }^{9}$ of the hypothalamus-pituitary-adrenal (HPA) axis found increased adrenocortical activity following bereavement, while 2 had negative findings. Altered adrenocortical activity seems to be present, especially in individuals with high levels of anxiety, depressed mood or intense grief.
Adrenocorticotrophic hormone (ACTH) response to corticotrophinreleasing hormone $(\mathrm{CRH})$ in individuals with complicated grief showed similar results to the above studies.

Dexamethasone non-suppression among bereaved patients was found to be higher than in normal controls, but not as high as in depressed outpatients. ${ }^{9}$

Elevated growth hormone levels have been found in patients experiencing anxiety because of loss of a marital partner. ${ }^{9}$

\section{Immune system}

Bereaved individuals showed significantly lower immunoglobulin $G(\lg G)$ and immunoglobulin A (lgA) titres than controls. One study ${ }^{9}$ showed significantly decreased T-suppressor cells, significantly increased Thelper cells and significantly increased levels of depression.

\section{Neurotransmitters}

Although it may be theoretically possible to study the neurochemical changes in the brains of bereaved individuals /using functional brain-imaging techniques such as positron emission tomography (PET)|, ethical considerations make it just about impossible to do so. Instead, we have to rely on primate studies that deal with separation of infant monkeys from their mothers. These studies show an increase in monoamine metabolite concentrations during the first days after separation and increased concentrations of methyl-hydroxyphenoglycol (MHPG) and a decrease in CSF homovanillic acid (HVA). CSF 5-hydroxyindolacetic acid (5H IAA) levels are inconclusive.?

\section{Associated psychiatric disorders}

\section{Major depressive disorder}

A study by Zisook et al., ${ }^{14}$ using DSM N criteria for major depression, identified that $20 \%$ of a bereaved sample suffered from a depressive episode 2 months post-loss. Longitudinal evaluation of the data found that the proportion decreased to $12 \%$ at 13 months post-loss and to $6 \%$ at 25 months post-loss.

Considerable mortality and morbidity are associated with depressive symptoms that persist for more than 8 weeks following loss of a spouse. Brief periods of bereavement-related distress should not be pathologised, but periods lasting several months that meet the criteria for major depressive episode (traumatic grief reaction) deserve careful assessment and treatment. ${ }^{15}$ 
Risk factors for the occurrence of major depressive disorder after the death of a spouse are as follows: when the surviving spouse experiences a full depressive syndrome early after the death; past personal or family history of major depression; lack of social support; overwhelmingly negative life events; female gender; younger individuals; financial loss; sudden and unexpected death; and an ambivalent relationship with the deceased person. ${ }^{14}$

\section{Anxiety disorders}

The most common anxiety disorder diagnosed in bereavement studies is generalised anxiety disorder (GAD), found in $23 \%$ of a 6-month bereaved sample and $39 \%$ of a 12-month bereaved sample. The community prevalence rate for GAD is $9 \%{ }^{3}$

The majority of depressed individuals in the 6-month bereavement sample $(63 \%)$ were also diagnosed with an anxiety disorder. Depression typically declines during the bereavement period, but it seems that more anxious, chronically bereaved individuals continue to suffer from enduring depression. ${ }^{3}$

In the early phases of bereavement there is a psychological and neurophysiological rekindling of the survivor's earliest experiences of insecurity, inadequacy and helplessness, which may contribute to higher likelihood of developing generalised anxiety, panic and phobic disorders. ${ }^{16}$

The following factors contribute to the development of substantial and prolonged anxiety in widowhood: younger age, female gender, loss of income because of the death, lack of social support, and experience of ongoing, acute grief, a depressive syndrome and anxiety symptoms 2 months after the loss. ${ }^{16}$

\section{Post-traumatic stress disorder (PTSD) Distinguishing traumatic grief from PTSD}

The question remains whether PTSD, like depressive/anxiety disorders, might be an adverse complication of bereavement. The most recent study by Breslau et al. ${ }^{17}$ found that the sudden and unexpected death of a close friend/relative was the most common trauma and the risk of PTSD in this group of patients was $16 \%$ in females and $13 \%$ in males.

Rynearson (quoted by Zizook ${ }^{18}$ ) emphasises the traumatic aspects of loss after homicide or suicide presenting with ongoing themes of violation, victimisation and volition. This underscores the primacy of PTSD phenomena over grief phenomena in non-recovery.

PTSD after 'ordinary' bereavement is associated with chronicity, co-morbidity and dysfunction similar to PTSD following more traditionally accepted traumatic stressors. ${ }^{19}$
Prigerson et al. ${ }^{8}$ identified a syndrome of 'traumatic grief' that is characterised by intense and prolonged preoccupation and thoughts of the deceased, yearning and searching behaviour, disbelief and avoidance resulting in a high rate of physical and psychological morbidity. Traumatic grief resembles PTSD but the trauma in the case of traumatic grief is a 'separation' type of trauma and includes symptoms of separation distress, e.g. yearning or searching. These symptoms are not included in DSM N criteria for PTSD. In traumatic grief the absence of the deceased is the distressing factor, rather than re-experiencing of the actual death. Hypervigilance and avoidance in PTSD play a lesser role in traumatic grief. ${ }^{8}$

Frank et al. ${ }^{15}$ recommend a specific 9-session intervention for the treatment of traumatic grief. The emphasis is on reliving the moment of death, saying goodbye to the deceased and in vivo exposure to situations that the person has avoided since the death.

\section{Treatment of pathological grief}

The appropriate recognition and treatment of individuals suffering from pathological grief aims to reduce the risk of developing psychiatric illness, particularly if the loss is sudden, and to prevent suicide, which has the highest occurrence in the first year of bereavement. ${ }^{20}$ Greater vulnerability to physical illness follows bereavement, with men being at higher risk for tuberculosis, pneumonia, cirrhosis, alcoholism, accidents, heart disease and cancer than women.?

We should remember though that conflicting views exist on the treatment of pathological grief, and that we have too little knowledge to claim that we know the best way to grieve. We should tell people to accept their emotions and cognitive reactions, that the passing of time usually has a dampening effect on emotions and a healing effect. We should recommend that the bereaved get involved in life again as soon as possible; in other words we should not pathologise bereavement unnecessarily. 'Grief is not only painful. Grief may also be meaningful.'21

\section{Psychotherapeutic intervention}

A range of therapeutic options are described in the literature - individual assessment of each case is advised so that there may be suitable intervention. 13,16,20,22

The following options exist: (i) individual bereavement therapy; (ii) family bereavement therapy; and (iii) group therapy. 


\section{Individual bereavement therapy}

In the existing literature the outcome of the intervention varies in type, duration, training of therapists and methodology. More research on the effect of individual therapy on bereavement is suggested. ${ }^{21}$ Pathological grief and the suggestion of specific treatment programmes are difficult to define. ${ }^{20}$

The following theories can be incorporated in the process of individual bereavement therapy.

\section{Psychoanalytic theory}

According to Freudian theory pathological grief results when an individual has a predisposition to obsessional neurosis, is ambivalent about the loss, and blames him/herself for it. Intervention using this theory therefore focuses on working through ambivalent feelings towards the deceased, resolving self-blame and encouraging the bereaved to re-invest his/her libido in a new love object.

\section{Stress theory ${ }^{21}$}

Bereavement is described as a major life stressor, which requires more adjustment than other life events. Bereaved who appraise the event as stressful are likely to have more adverse outcomes. Intervention is based on cognitive and behavioural changes, e.g. helping the bereaved to find ways to see the event as within their coping capacities. The focus of intervention should be on those at greatest risk of maladaptive grief reactions. Behavioural intervention may address the adjustment of behavioural patterns (eating, exercising and sleeping), which may have an impact on health outcomes.

At what point counselling becomes psychotherapy has never been well defined; however, studies of psychotherapeutic techniques for the bereaved have extended the understanding of important ways to help bereaved people, especially those with bereavement-related pathologies and problems. ${ }^{20}$

Management of pathological grief follows Lindeman's original principles, namely to convert pathological grief to normal grief. ${ }^{20}$

The following factors are important to consider in the treatment of pathological grief. ${ }^{20}$

Delayed or absent grief. The therapeutic task involves the identification of contributing factors, paying particular attention to: (i) current severe life stressors; (ii) past severe deprivation (gross lack of parenting or absence of attachments and loss by death of a parent in childhood) - these patients may need skilled and in-depth psychotherapy; (iii) personality patterns and coping that rely strongly on denial or repression of affect; (iv) quality of the attachment; and ( $v$ ) presence of a major psychiatric disorder.

The emphasis in therapy would be exploring the reasons for denial, and confronting and working through the realities of the loss. Regrief work and therapeutic rituals may be helpful.

Inhibited grief may be on a continuum with absent grief and may include excessive anger or guilt, with the absence of significant grieving. The abovementioned may relate to experiences of dependency and/or ambivalence in the preexisting relationship with the deceased and may result in conflicted grief or clinging grief.

The aim of therapy in this instance would be completion of the tasks of grieving, viz. accepting the reality of the loss, experiencing the pain of grief, re-defining the relationship with the deceased, adjusting to the environment, and finally withdrawing emotional energy and re-investing in other relationships.

Chronic grief. In the case of intense and prolonged grief, the bereaved may appear to be in a recent state of loss even though many years may have passed. Crying, intense preoccupation and idealisation of the deceased are common.

The bereaved's life may have become a memorial to the dead person, at considerable cost to other family members and to personal relationships. This is especially the case with loss of a child.

Chronic grief is very difficult to treat; the bereaved is usually reluctant to relinquish preoccupation with the deceased.

Depression often co-exists and should be treated appropriately, but a core syndrome of chronic grief is still likely to be resistant to therapeutic intervention.

\section{Family bereavement therapy}

Goals of therapy are to improve family functioning, increase cohesiveness, improve communication, and foster conflict resolution. The family relationships index (FRI) developed by Meos can be used to screen dysfunctional families and those at risk, and help to achieve better family functioning and improve psychosocial outcome of grief. ${ }^{22}$ Families at risk are those where one or more respondents score 9 or less out of 12, or less than 4 on cohesiveness.

This approach to bereavement attempts to be focused and time-limited and not to be drawn into longstanding personality 
problems in the family. The therapy can be initiated before death in the case of terminally ill patients.

\section{The course of therapy}

Therapy progresses through five sequential phases, namely assessment, identification of relevant issues, focused treatment, consolidation and ending. The programme runs for 6 - 8 sessions, extending across 6 or more months (frequency flexible), with a typical session lasting $1 \frac{1}{2}$ hours.

\section{Common themes covered in therapy}

Common therapeutic themes include: (i) death; (ii) saying goodbye (completing of unfinished business); (iii) care provision (practical planning and problem-solving approach); (iv) suffering (dealing with the emotional pain of loss); ( $v$ ) intimacy; (vi) cultural and religious practices; (vii) younger children; (viii) historical issues (past relationship breakdowns, bereavements, disappointments); (ix) good death or disappointment; (x) grief.

In the final phases of therapy the family is invited to look to its future, reviewing priorities and needs. They are reminded that old issues are likely to recur.

\section{Group therapy}

Group intervention can be carried out by professionals alone, or in conjunction with bereaved persons.

Groups can be structured in different ways. ${ }^{23}$

In self-help groups participants assist each other in problem solving.

Confidence groups focus on the development of close friendships between group members.

Consciousness-raising groups examine the relationship between a series of sex-role topics and widowhood, among other things.

Support groups concentrate on education and lectures on the grieving process and on open discussion, group counselling, freedom to vent feelings, instruction in relaxation techniques, journal writing, writing a letter to the deceased and creating a memorial for the deceased.

Support groups for bereaved males may focus on different aspects than widow groups. ${ }^{13}$ Bereaved males have fewer role models than their bereaved counterparts and are less apt to know how to initiate contact with other men in similar circumstances. They may need encouragement to move beyond traditional gender roles in order to cope with demands within the family.

\section{Socio-cultural differences in experiencing grief ${ }^{24}$}

Culture-bound assumptions (often westernised beliefs) should be questioned regarding the normal course of grief. Such assumptions focus on individuals rather than relationships, deny the enduring nature of important attachments, and pathologise variations from the cultural norm.

The medical and mental health field has become a subculture with its own beliefs regarding grieving families, e.g. that grief is a private experience, that immediate and open expression of feelings is necessary for healthy resolution of grief, that bereavement has a specified endpoint, and that an ongoing relationship with images of the deceased is pathological

Bereavement therapy is one of the areas of mental health work in which assessment of a family's relationship to cultural traditions is important, even in the case of families that appear acculturated to a secular Western culture.

Under the stressful circumstances of lifecycle transition, individuals and families are more likely to draw on ideological ethnicity, i.e. customs and beliefs that are not fundamental to a person's daily life in order to create intergenerational continuity that will balance the disorientating process of rapid chance precipitated by death. Therapists can help to identify cultural resources and to generate meaningful rituals that enhance the family's cultural and ancestral ties.

\section{Psychopharmacological intervention}

One study ${ }^{15}$ compared interpersonal psychotherapy with nortriptyline treatment. The outcome in the 17-item Hamilton Rating Scale for Depression (HRSD) scores was a change from $19.8 \pm 3.5$ to 7.6 in the nortriptyline-treated group and $18.5 \pm$ 2.3 to $7.2 \pm 4.6$ in the psychotherapy group

No placebo-controlled studies have been reported regarding psychopharmacological intervention in the treatment of pathological grief. This remains an area open for future research. In my own clinical experience the treatment of especially major depressive disorder using antidepressant medication and individual bereavement therapy seems to have an excellent outcome in terms of the completion of the bereavement process and continuation with life. The antidepressant treatment is exactly the same as for major depression (i.e. type of antidepressant, dosage and length of treatment). 


\section{REFERENCES}

1. Rotter JC. Family grief and mourning. The Family Journal: Counselling and Therapy for Couples and Families 2000; 8: 275-277.

2. Rosenzweig A, Prigerson H, Miller MD, Reynolds CF. Bereavement and late-life depression: grief and its complications in the elderly. Annu Rev Med 1997: 48: 421 428

3. Bonnanno GA, Kaltman S. The varieties of grief experience. Clin Psychol Rev 2001 21: $705-734$

4. Shuchter SR, Zisook S. The course of normal grief. In: Stroebe MS, Stroebe W Hansson RO, eds. Handbook of Bereavement. Cambridge: Cambridge University Press, 1993: 23-43

5. Romanoff BD, Terenzio M. Rituals and the grieving process. Death Studies 1988; 22 697-711

6. Middleton W, Raphael B, Martinek N, Misso V. Pathological grief reactions. In: Stroebe MS, Stroebe W, Hansson RO, eds. Handbook of Bereavement. Cambridge: Cambridge University Press, 1993: 44-61.

7. American Psychiatric Publishing, Inc. Diagnostic Criteria from DSM-IV. Washington, DC: APA, 2005: 290

8. Prigerson HG, Shear MK, Jacobs SC. Consensus criteria for traumatic grief. BrJ Psychiatry 1999; 174: 67-73

9. Biondi M, Picardi A. Clinical and biological aspects of bereavement and loss-induced depression: A reappraisal. Psychother Psychosom 1996; 65: 229-245.

10. Sanders CM. Risk factors in bereavement outcome. In: Stroebe MS, Stroebe W Hansson RO, eds. Handbook of Bereavement. Cambridge: Cambridge University Press, 1993: 255-267

1 1. Szanto K, Prigerson H, Houck P, Ehrenpreis L, Reynolds CF. Suicidal ideation in elderly bereaved: The role of complicated grief. Suicide and Life Threatening Behaviour 1997; 27: 195-207

12. Martin JL, Dean L. Bereavement following death from AIDS: Unique problems, reactions, and special needs. In: Stroebe MS, Stroebe W, Hansson RO, eds.
Handbook of Bereavement. Cambridge: Cambridge University Press, 1993: 317 330

13. Carverhill PA. Bereaved men: How therapists can help. Psycotherapy in Private Practice 1997; 16: 1-15

14. Zisook S, Shuchter SR. Depression through the first year after death of a spouse. Am J Psychiatry 1991; 148: 1346-1352

15. Frank E, Prigerson HG, Shear MK, Reynolds CF. Phenomenology and treatment of bereaved-related distress in the elderly. International Clinical Psycopharmacology 1997: 12: suppl 7, S25-\$29.

16. Lindstrom TC. 'It ain't Necessarily So'... challenging mainstream thinking about bereavement. Fam Community Health 2002; 25(1): 11-21.

17. Breslau N, Kessler RC, Chilcoat HD, Schultz LB, Davis GC, Andreski P. Trauma and post-traumatic stress disorder in the community: The 1996 Detroit area survey of trauma. Arch Gen Psychiatry 1998; 55: 626-682

18. Zisook S, Chentsova-Dutton Y, Shuchter SR. PTSD following bereavement. American Academy of Clinical Psychiatrists 1998; 10: 157-163.

19. Zisook S, Schneider D, Shuchter SR. Anxiety and bereavement. Psychiatric Medicine 1990; 8 (2): 83-95

20. Raphael B, Middleton W, Martinek N, Missus V. Counselling and therapy of the bereaved. In: Stroebe MS, Stroebe W, Hansson RO, eds. Handbook of Bereavement Cambridge: Cambridge University Press, 1993: 427-453

21. Kato PM, Mann T. A synthesis of psycological interventions for the bereaved. Clin Psychol Rev 1999; 19: 275-296

22. Kisane DW, Bloch S, McKenzie M, McDowall AC, Nitzan R. Family grief therapy: A preliminary account of a new model to promote healthy family functioning during palliative care and bereavement. Psycho-Oncology 1998; 7: 14-25.

23. Stylianos K, Vachon MLS. The role of social support in bereavement. In: Stroebe MS, Stroebe W, Hansson RO, eds. Handbook of Bereavement. Cambridge: Cambridge University Press, 1993: 397-410.

24. Shapiro E. Family bereavement and cultural diversity: A social developmental perspective Family Process 1996: 35: 31 3-332. 